\title{
As teias de interesses e influências nas redes de políticas educativas na América Latina e Caribe
}

\author{
The ties of interest and influence on educational policy networks in \\ Latin America and the Caribbean
}

\section{Las teias de intereses y influencias en las redes de políticas educativas en América Latina y Caribe}

\begin{abstract}
Letícia Fiera'
Secretaria de Educação do Estado de Santa Catarina, Professora; Grupo de Investigação em Política Educacional (G,ipe-Marx/UFSC); Núcleo de Estudos sobre Sistema Financeiro (Nesfi/ UFSC), Pesquisadora.

https://orcid.org/0000-0003-0310-0800
\end{abstract}

\begin{abstract}
Resumo: Neste artigo procura-se compreender as múltiplas determinações em relação ao compromisso com a privatização da educação pública latino-americana. Observa-se a constituição de uma rede política de grupo de empresários, grupos econômicos, instituições financeiras e organismos multilaterais que se organizaram e se articularam para incidir nas tomadas de decisões nas políticas educativas dos países latino-americanos, notadamente o Movimento Todos pela Educação, no Brasil, e a Rede Latinoamericana de Organizações da Sociedade Civil para a Educação. No desenvolvimento metodológico, procedemos ao levantamento e análise de fontes primárias (documentos oficiais, institucionais e relatórios) e secundárias (pesquisas e produções sobre o tema). Além disso, utilizamos a metodologia de análise de redes sociais. Como resultado, observamos que as redes influenciam nas estratégias e alianças que nos permitem compreender de forma mais complexa a interdependência e o contexto da política públicas em educação.
\end{abstract}

Palavras-chave: Redes de políticas públicas. Governança. Movimento Todos Pela Educação. Rede Latino-americana de Organizações da Sociedade Civil para a Educação.

Abstract: This article seeks to understand the multiple determinations regarding the commitment to the privatization of public education in Latin American. It is observed the constitution of a network political of group of businessmen, economic groups, financial institutions and multilateral organizations that were organized and articulated to focus in the decision making in the educational politics in the Latin American countries, notably the Movement Education for All, in Brazil, and the Latin American Network

Doutora em Sociologia e Ciência Política pela Universidade Federal de Santa Catarina; Mestre em Ciência da Linguagem pela Université Paris Nord. 
of Civil Society Organizations for Education. In the methodological development, we proceeded to the survey and analysis of primary sources (official documents, institutional and reports) and secondary sources (researches and productions on the subject). In addition, we use the social network analysis methodology. As a result, we observe that networks influence strategies and alliances that allow us to understand more interdependently and the context of public policy in education.

Keyword: Network political public. Governance. Movement Education for All. Latin American Network of Civil Society Organizations for Education.

Resumen: En este artículo se busca comprender las múltiples determinaciones en relación al compromiso con la privatización de la educación pública latinoamericana. Se observa la constitución de una red política de grupo de empresarios, grupos económicos, instituciones financieras y organismos multilaterales que se organizaron y se articular para incidir en las tomas de decisiones en las políticas educativas en los países latinoamericanos, especialmente el Movimiento Todos por la Educación, en Brasil, y la Red Latinoamericana de Organizaciones de la Sociedad Civil para la Educación. En el desarrollo metodológico, procedemos al levantamiento y análisis de fuentes primarias ldocumentos oficiales, institucionales e informes) y secundarias (investigaciones y producciones sobre el tema). Además, utilizamos la metodología de análisis de redes sociales. Como resultado, observamos que las redes influyen en las estrategias y alianzas que nos permiten comprender de manera más interdependiente y el contexto de las políticas públicas en educación.

Palabras clave: Redes de políticas públicas. Gobernabilidad. Movimiento Todos por la Educación. Red Latino-americana de Organizaciones de la Sociedad Civil para la Educación.

Recebido em 31 de maio de 2019

Aceito em 4 de setembro de 2019

Publicado em 19 de dezembro de 2019

\section{INTRODUÇÃO}

Este artigo procura expor, ainda que de forma parcial, a estruturação e organização da burguesia latino-americana para a manutenção e atualização de suas estratégias de dominação e acumulação do capital, tendo em vista ultrapassar o seu fantasmagórico mundo das aparências e alcançar o concreto pensado que a constitui. Tanto a estruturação quanto a organização da classe burguesa são determinantes para a consolidação da formação de redes políticas de interesse nas reformas educativas latino-americanas sob a égide dos princípios da, dada como inexorável, globalização financeira. 
0 estudo realizado pela Campanha Latino-americana pelo Direito à Educação, Mapeo sobre Tendencias de la Privatización de la Educación en América Latina y el Caribe (2014), resultou em uma amostragem dos processos de privatização da educação que vêm ocorrendo na região ao apontarem para a fragilização dos sistemas públicos educativos, resultados de uma desvalorização do corpo docente e estudantes, de gestão democrática de pouco impacto, de criminalização de movimentos e ativistas sociais e, por fim, de baixo financiamento público. Ball e Youndell (2007) identificam algumas tendências de privatização em muitos países em desenvolvimento, como a transferência de competências, as associações entre $\circ$ setor privado e $\circ$ público, especialmente caracterizadas pelos novos projetos de educação adotados pela região com múltiplas fontes de financiamento, ressaltando-se o papel desempenhado do Banco Mundial.

Isso exige um esforço para compreender o contexto pol'tico latino-americano, marcado pela reforma dos Estados Nacionais, principalmente a partir dos anos de 1990. Ao longo desse periodo, o Estado sofreu alterações nas relações entre o público e o privado, em um contexto de crise estrutural do capital (MÉSZÁROS, 2009). Ball e Youndell (2007) consideram que essas reformas do setor público estão relacionadas com as mudanças nas formas e modalidades do Estado moderno, isto é, como realiza suas ações e alcança seus objetivos, as mudanças no processo polticico e os novos métodos para governar. De acordo com os pesquisadores, está ocorrendo a passagem para a governança, ou seja, passa-se de um governo de Estado para a governança por meio da filiação de objetivos e de supervisão do uso de diversos participantes e provedores para conduzir a politica e oferecer programas e serviços.

As diferentes manifestações da privatização da educação pública latino-americana por meio das parcerias público-privadas (PPP) se evidenciam nos contratos de gestão, termos de cooperação, que formam "quase-mercados", em que a propriedade permanece pública, mas o conteúdo da gestão é privado. As reformas educacionais implementadas nos últimos anos na América Latina e Caribe sofreram influências de organizações multilaterais ao incorporar metas e diretrizes definidas em encontros internacionais (Jomtien/1990; Nova Deli/1993; Dakar/2000; Incheon/2015) nos quais participaram governos, agências internacionais, organismos não governamentais, entre outros. As mudanças ocorridas na educação na região, nas últimas décadas, têm demonstrado o impacto da atual fase do capitalismo como condição necessária para a subordinação da educação perante o capital.

Com essa perspectiva, empresários, grupos econômicos, instituições financeiras e organismos multilaterais organizaram uma rede para intervir nas tomadas de decisões em matéria de política educativa nos paises. Isso evidencia as determinações econômicas das políticas educacionais pela crescente investida do setor privado por meio de formas de organizações (redes e organizações não-governamentais) pelas quais o capital, a fim de manter-se e reproduzir-se, sustenta o discurso acerca da modernização da Educação. 
Apresentamos, pois, um diagnóstico do processo de atualização das formas de dominação burguesa: no Brasil, temos a presença do Movimento Todos pela Educação (TPE); na América Latina e Caribe, a Rede Latino-americana de Organização da Sociedade Civil para a Educação (Reduca). Esse caminho analítico-descritivo proporciona observar a constituição de uma rede transnacional e transassociativa de interesses de classe na América Latina e Caribe.

No que tange ao desenvolvimento metodológico, procedemos ao levantamento e análise de fontes primárias (documentos oficiais, institucionais e relatórios) e secundárias (pesquisas e produções sobre o tema). Focamos principalmente o Relatório do Seminário Internacional sobre Privatização na Educação, organizado pela Campanha Latino-americana pelo Direito à Educação, Mapeo sobre tendencias de la privatización de la Educación en América Latina y el Caribe (2014), o relatório Repensar a educação da UNESCO (2016).

Nossa análise foi subsidiada pelas abordagens de Mészáros (2005, 2009), Harvey (1993, 2003), Chesnais $(2004,2005)$, autores fundamentais para a compreensão do capitalismo contemporâneo. Além disso, utilizamos a metodologia de Análise de Redes Sociais (ARS), desenvolvida para o exame de dados relacionais, aqueles que evidenciam laços, contatos, vínculos, conexões que unem indivíduos ou organizações entre si. 0 termo rede pode ser compreendido como um "agrupamento de instituições", mas também como "forma e estrutura de organização e funcionamento". A metodologia de ARS oferece a possibilidade de identificar sujeitos e organizações inseridos em uma teia de conexões. Neste trabalho, as extrações de medidas relacionais foram realizadas por meio do programa UCINET e a geração de grafo mediante o programa NetDraw.

\section{POLÍTICAS EDUCACIONAIS SOB A ÉGIDE DA GLOBALIZAÇÃO FINANCEIRA}

Nas sociedades capitalistas, o elemento central da economia é o capital. 0 capitalismo, como ensinaram Marx e Engels (2010), é uma sociedade na qual trabalhadores e burgueses são analisados como classes sociais, no entanto, essas são, ao mesmo tempo, antagônicas, uma vez que as classes sociais não se definem separadamente, mas nas relações que mantêm entre si. Portanto, o caráter antagônico das classes sociais no capitalismo nasce da subordinação das relações sociais em relação ao processo de valorização do capital. As prioridades do capital sempre foi a extração de mais-valia na produção de mercadorias e serviços e, principalmente, a centralização do capital na forma monetária cujo poder está centrado na reprodução da esfera financeira. 
A atual fase do capitalismo conhecida como globalização, nasce da combinação entre as inovações tecnológicas advindas da indústria eletrônica e consubstanciada na popularização e difusão da informática com a desregulamentação dos mercados em suas três esferas (comercial, investimentos e financeira) a partir do final dos anos de 1970. Têm-se, portanto, duas determinações causais: uma de origem técnica e outra de origem política que agem simultaneamente, embora a segunda ordem de fatores tenda a ser subestimada por um discurso ideológico que sublinha a natureza "moderna" e "irreversível" das transformações ocorridas nos últimos 25 anos (CHESNAIS, 2004).

As transformações no sistema capitalista internacional, desde os anos de 1970, redefiniram a estrutura do setor financeiro e, com isso, as redes corporativas financeiras e políticas estabeleceram novas conexões e constelações de interesses, com impacto direto sobre o sistema econômico e a sociedade, formando o que Chesnais (2005) classifica como processo de hegemonia financeira sobre a produção por meio da financeirização do capital.

Harvey (1993, p. 15) considera que a globalização financeira significa uma completa reorganização dos sistemas financeiros globais e a emergência de poderes imensamente ampliado de coordenação financeira, tendência caracterizada pelo seguinte movimento "[...] de um lado, para a formação de conglomerados e corretores financeiros de extraordinário poder global; e, de outro, uma rápida proliferação e descentralização de atividades e fluxos financeiros por meio da criação de instrumentos e mercados financeiros totalmente inéditos." (HARVEY, 1993, p. 15).

0 novo arranjo dos mercados financeiros de fato atendia com mais eficiência os requisitos do regime de acumulação flexível, com suas rápidas mudanças de processos e bases industriais e a consequente necessidade de expansão e financiamento. Assim, para atender as novas demandas do capitalismo, os sistemas financeiros ganharam mais autonomia e assumiram papel específico, uma vez que trataram de otimizar as cadeias produtivas para lucrar em todas as áreas. Este é o significado concreto da articulação entre as políticas educativas adotadas pelo governo brasileiro e o sistema produtivo nas últimas décadas.

As características mais conhecidas do neoliberalismo são o recurso ao mercado e a diminuição do papel econômico do Estado. Mas é necessário desconfiar deste aspecto, pois o Estado não desaparece com o neoliberalismo; o que desaparece é o Estado keynesiano, o welfare state. A questão aqui é compreender que os fundamentos da liberalização e da desregulamentação foram tanto políticos quanto econômicos. Segundo Chesnais (2005, p. 18), 
doméstico e a mobilidade internacional [...] necessitaram numerosas medidas legislativas e regulamentares.

0 neoliberalismo quis adaptar o sistema de educação ao novo contexto da organização do trabalho mais "flexível", enfraquecer "tudo o que faz contrapeso ao poder do capital" (LAVAL, 2004, p. 14). Nesta perspectiva de longo prazo, compreender as múltiplas determinações em relação ao compromisso com a privatização da educação pública na América Latina e Caribe permite observar no interior das relações econômicas internacionais uma agenda globalmente estruturada (DALE, 2004) para a subordinação da educação ao capital. À medida que o papel do Estado diminui, entram na arena política atores privados, com ou sem fins lucrativos - caso específico das Organizações Não Governamentais (ONG) e Organizações da Sociedade Civil de Interesse Público (OSCIP) -, atuando na consolidação do setor privado dentro do próprio setor público de educação.

A privatização da educação foi, em menor ou maior escala, aceita e implementada por esses governos, como observa Evangelista (2012), articulada à reforma do Estado e ao ajuste estrutural da economia sob o viés da política neoliberal em curso na região. A hegemonia financeira foi um estímulo para a organização na Sociedade Civil desses sujeitos implicados na defesa de seus próprios interesses. Ao averiguarmos, no movimento histórico, as novas estratégias do capital, mediante a estruturação e a organização da burguesia latino-americana, defrontamo-nos com sua ação para a manutenção e atualização de dominação e acumulação, bem como sua articulação e mobilização para interferência direta na elaboração de políticas educacionais na América Latina e Caribe.

\section{O MOUIMENTO TODOS PELA EDUCAÇÃO E OS GRUPOS ECONÔMICOS}

Uma questão imediata deriva da realidade apontada na seção antecedente: as reformas nas políticas educacionais implementadas pelos governos brasileiros nas últimas três décadas dizem respeito à indicação de sujeitos com maior vínculo com o sistema financeiro, empresas privadas, centros acadêmicos e instituições alinhadas ao Consenso de Washington e à organizações multilaterais. A redefinição do papel do Estado nesse período histórico e como se materializou no Brasil, a partir do Plano Diretor da Reforma do Aparelho do Estado Brasília (1995), instituiu a administração pública gerencial no mandato do presidente Fernando Henrique Cardoso (1994-2001), observando-se continuidades nas gestões do presidente Lula da Silva (2003-2010), da presidenta Dilma Rousseff (2011-2016) e de Michel Temer (2016-2018). 
Nesse processo histórico, concreto, de relações de classes e no interior da correlação de forças em curso, o capital detém a hegemonia.

Encontramos na teoria marxista uma discussão acerca das condições de produção capitalista que ocasionam um processo de concentração e centralização do capital. Como sabemos, a dinâmica de acumulação de capital implica a absorção dos pequenos capitalistas pelos grandes, ocasionando uma centralização, e também significa a ampliação da base de produção em larga escala acarretando na concentração. A análise da concentração e da centralização de capitais elaborada por Marx, em 0 Capital (2017), contém indícios importantes para a explicação do aparecimento dos monopólios, a partir de uma determinada fase de desenvolvimento do capitalismo. Marx (2017) demonstra como os monopólios são o resultado lógico do processo de acumulação de capitais. A concentração da produção e do capital em grandes empresas é a consequência inevitável do desenvolvimento capitalista. Harvey (2003) assinalou, com base nos estudos de Marx, que a competição tende sempre ao monopólio (ou oligopólio), simplesmente porque a sobrevivência do mais apto na guerra de todos contra todos elimina as empresas mais fracas. Quanto mais feroz a competição, mais veloz a tendência ao oligopólio, para não dizer monopólio. Portanto, não é por acidente que a liberalização dos mercados e a celebração da competição nos últimos anos produziram uma incrível centralização de capital.

Nesse cenário, sujeitos de interesse do capital vêm-se inserindo na gestão das políticas educacionais por meio de suas organizações, as quais desenvolvem estratégias, colocando-se na arena política como agentes do poder econômico, mas também como atores de políticas, parceria construída historicamente que encontrou eco no contexto de crise estrutural do capital. Para Mészáros (2009), a educação é radicalmente atingida pelos interesses do capital, cujos métodos impõem a necessidade de reformas via reformulação (permanente) de diretrizes e estratégias elaboradas pelos organismos internacionais. 0 papel do Estado na gestão das políticas educacionais vai ser rediscutido, pois amplia-se a participação do setor privado na esfera pública; vê-se, portanto, uma rápida expansão das parcerias público-privadas na educação.

Ao mesmo tempo, deve-se reconhecer o poder que os grupos econômicos têm sobre os mercados e a sociedade em geral, sua capacidade de instituir valores e de se transformarem em instrumento político, além de controlarem substantivos fluxos de capitais que thes garantem capacidade de vetar decisões de regulação pública, relativizar o poder do Estado e afetar a economia de diversos países (PORTUGAL JÚNIOR, 1994, p. 55-56). Na nova ordem educativa, como considera Laval (2004), o sistema educativo está a serviço da competividade econômica, estruturado como mercado e deve ser gerido ao modo de empresas.

Perguntamos: o que motiva um grupo econômico a aplicar seu capital no setor da educação? Robertson e Verger (2012) parecem dar a resposta ao considerar o setor da 
educação como um campo para potenciais investimentos em serviços, desde que sejam estabelecidas condições para a realização do lucro. Logo, a privatização da educação se tornou um ideal que foi interpretado e traduzido de muitas maneiras. Com a introdução dos modelos empresariais na gestão educacional, o capital encontra a possibilidade de se reproduzir ao ter o Estado como garantia de suas possíveis perdas.

A fim de termos uma compreensão objetiva do monopólio do poder instaurado pelo Movimento Todos Pela Educação nas políticas educativas, cabe salientar que os estudos sobre grupos econômicos formam um campo de análise bastante relevante na sociologia econômica, abarcando uma variedade muito ampla de abordagens teóricas que problematizam questões tradicionais da economia. Além disso, o conceito de grupo econômico permite, como considera o economista Gonçalves (1991), superar a dicotomia firma/mercado presente nas análises econômicas mais tradicionais. Reinaldo Gonçalves (1991, p. 494) define grupo econômico como

\footnotetext{
[...] o conjunto de empresas que, ainda quando juridicamente independentes entre si, estão interligadas, seja por relações contratuais, seja pelo capital, e cuja propriedade (de ativos específicos e, principalmente, do capital) pertence a indivíduos ou instituições, que exercem o controle efetivo sobre este conjunto de empresas.
}

Com fundamento no que foi expresso acima, é possivel observar sujeitos econômicos para além das descrições jurídicas das empresas e pensá-los como agência econômica produzida pela articulação de um conjunto de instituições, cujas características se apresentam como "um lócus de acumulação que detém o grande poder econômico e financeiro, e se subordina a um centro de controle estratégico único" (PORTUGAL JÚNIOR, 1994, p. 25).

0 TPE, fundado em 7 de setembro de 2007, se posiciona como um movimento da sociedade brasileira que tem como principal missão engajar o poder público e a sociedade civil no comprometimento efetivo do direito das crianças e jovens a uma Educação Básica de qualidade. Em 19 de fevereiro de 2014, se qualificou no mercado como OSCIP. Em seu estatuto, elenca como principais objetivos garantir o acesso à escola, à alfabetização e ao sucesso escolar, a ampliação de recursos investidos na Educação Básica e a melhoria da gestão dos recursos. Constituiu-se em terreno no qual se aglutinam interesses das mais diferentes frações da burguesia interessadas em afirmar seu comprometimento com a garantia do direito a uma Educação de qualidade. De acordo com Martins (2009), é possível afirmar que - TPE se materializou como organismo comprometido com as estratégias de hegemonia da classe empresarial no campo da educação e que sua inserção na sociedade civil, embora definida como "uma aliança" de esforços para o bem da nação, se afirma como estratégia para obter consenso em torno de um projeto criado e dirigido pela classe empresarial. Segundo Leher (2015), trata-se de um complexo muito sofisticado que interage com as frações 
burguesas dominantes, as políticas de Estado e os meios operativos do Estado para viabilizar sua agenda educacional.

A sua estrutura organizacional é bem definida em termos técnicos e políticos. É constituída por uma Presidência, ocupada por um empresário articulador da organização; um Conselho de Governança, com dezesseis empresários ou representantes de empresas; um Comitê Gestor, com seis dirigentes, sendo cinco deles empresários; uma Comissão de Comunicação, com seis membros ligados a grupos empresariais; uma Comissão de Articulação, com doze membros (empresários, lideranças de movimentos sociais, representante da lgreja Católica, representante da Unesco, representante do Ministério da Educação); uma Comissão Técnica, com dezesseis membros, predominantemente empresários; uma Comissão de Relações Institucionais, ocupada por um empresário; uma Equipe Executiva, com dez membros (não-empresários), sob a direção de uma Presidência-Executiva a cargo de um intelectual orgânico do capital com trajetória na educação superior (MARTINS, 2009).

Segundo o estatuto do TPE, o quadro de associados é constituído por quatro categorias, pessoas físicas e jurídicas, admitidas pelo Conselho de Governança, em referendo da Assembleia Geral. São eles: associado fundador (pessoas físicas que firmaram presença durante a assembleia de constituição do TPE; associado institucional (pessoa jurídica de notória e relevante capacidade de articulação de forças sociais em benefício da Educação, convidadas pelo Conselho de Governança); associados mantenedores (pessoa física ou jurídica que contribuam financeiramente com o TPE); associado efetivo (pessoa jurídica que queira colaborar para a consecução dos objetivos sociais da entidade).

Chama a atenção o Artigo 22 que estabelece que a quantidade de votos de cada membro Associado Mantenedor tomará por base suas contribuições financeiras para - TPE durante o período de doze meses. Para fins de cálculo dos votos, o parágrafo único estabelece a quantia de $\mathrm{R} \$ 100.000,00$, atualizada anualmente pelo IGP/FGV, ${ }^{2}$ correspondendo a um voto na assembleia. Cabe ao Conselho de Mantenedores atividades diretamente relacionadas às contribuições financeiras para a entidade TPE. A tabela abaixo representa as 13 mantenedoras do Todos pela Educação.

20 Índice Geral dos Preços (IGP) é um cálculo realizado para medir a evolução dos preços no mercado nacional, a Fundação Getúlio Vargas (FGV) é o órgão responsável para efetuar este índice. 


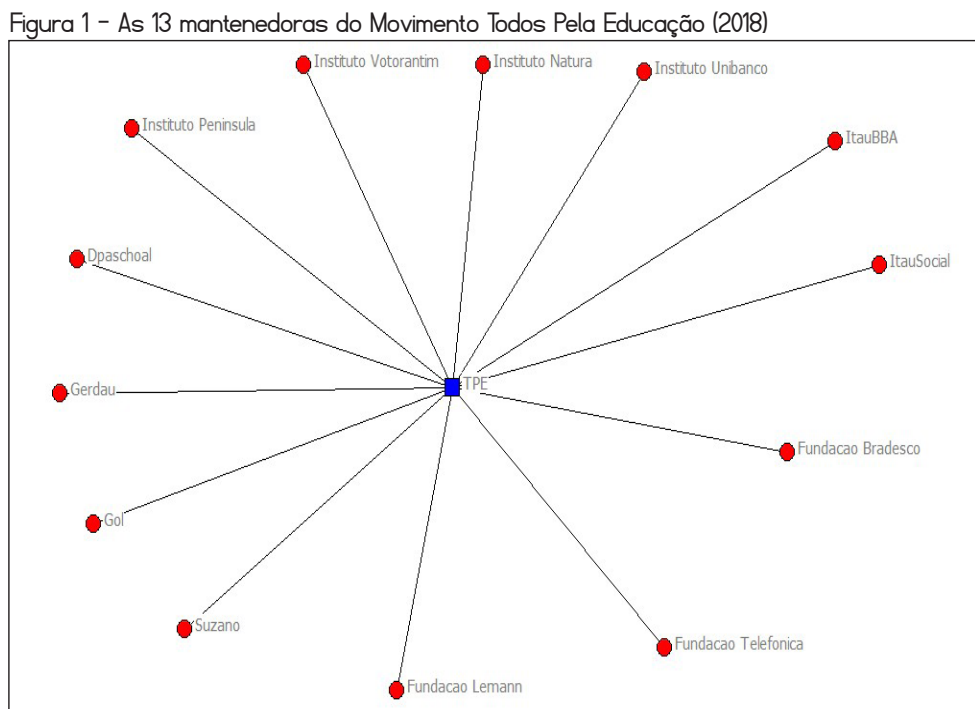

Fonte: $\mathrm{o}$ autor.

Neste conjunto, os grupos econômicos são do setor financeiro, agronegócio, mineral, meios de comunicação e companhias de aviação. Destaca-se a presença de quatro grandes instituições financeiras: Itaú, Unibanco, Lemann e Bradesco.

No que se refere aos bancos e instituições financeiras altamente poderosas dos mercados financeirizados, Minella (2006, p. 248-249, grifo do autor), sustentando-se em Mintz e Shwartz (1985), afirma que

0 fator fundamental para entender o poder dos bancos e das instituições financeiras é o controle que exercem sobre parte substantiva dos recursos e do fluxo de capitais na economia. Através deste controle são capazes de impor constrangimentos ao processo decisório das políticas governamentais e das decisões estratégicas das empresas, caracterizando-se um processo que alguns autores identificam como "hegemonia financeira".

Diante dessa perspectiva, é importante considerar que esses grupos econômicos encontraram no setor da educação um meio de reprodução do capital. Os grandes grupos econômicos presentes na composição das mantenedoras do movimento TPE têm desempenhado papel estratégico para cimentar o consenso quanto à hegemonia do capital financeiro.

Nosso escopo não é traçar um perfil sociopolítico de cada mantenedor que faz parte do movimento TPE. No entanto, vale salientar que dos 13 grupos, seis têm forte ligação com o sistema financeiro: Instituto Unibanco, Itaú BBA, Fundação Lemann, Fundação Bradesco, 
Instituto Votorantim e o Itaú Social. Apesar de Itaú e Unibanco aparecerem de forma distinta no quadro acima, seja através de institutos ou com o próprio selo que garante a presença da empresa, os bancos Itaú e Unibanco formam um único grupo. Em novembro de 2008, Itaúsa e Unibanco Holding anunciaram a fusão de suas operações financeiras; com isto tornou-se - maior conglomerado financeiro do hemisfério Sul, fazendo parte da lista dos 20 maiores bancos do mundo. Em 2012, o Itaú Unibanco entrou no ranking da Revista Forbes como a 30 maior empresa do mundo.

0 Itaú Unibanco realiza grandes investimentos em cultura e educação. Existem quatro principais instituições que se ocupam destes setores: Instituto Moreira Salles e Instituto Unibanco (criados pelo Unibanco), Fundação Itaú Social e Instituto Itaú Cultural (criados pelo Itaú). Apesar da fusão entre os bancos, as quatros instituições seguem suas atividades de acordo com critérios, linhas de trabalho e procedimento anteriores, o que pode ser percebido pela continuidade de programas considerados concorrentes (URBINI, 2015).

Os mantenedores do TPE, além de contribuírem financeiramente para a efetiva ação do movimento, oferecem programas vinculados às instituições e às fundações no ramo de tecnologias de ensino e gestão, ao realizarem cursos de formação de professores e demais trabalhadores, elaboram e implementam o uso de apostilas e manuais didáticos e de formação, desenvolvem ambientes virtuais de aprendizagem e de troca de informação entre as unidades escolares e secretarias de ensino.

A prática dos empresários brasileiros, desde o início dos anos de 1990, foi a de organizarem fóruns e documentos que direcionavam para a construção de uma agenda educacional apontada à "produção de uma nova sociabilidade mais adequada aos interesses privados do grande capital nacional e internacional" (SHIROMA; GARCIA; CAMPOS, 2011, p. 227). Nesta perspectiva, é preciso compreender a composição da rede de política pública deste movimento empresarial, pois segundo Shiroma, Garcia e Campos (2011, p. 233), foi "criado por um grupo de intelectuais orgânicos do capital" que, durante dois anos, com apoio dos meios de comunicação, realizaram eventos dialogando com sindicatos, sociedade educacional e civil. "Os empresários se antecipam e pautam a agenda governamental: reafirmam o papel do Estado redefinindo, no entanto, o sentido e o significado da educação pública" (SHIROMA; GARCIA; CAMPOS, 2011, p. 226).

\subsection{O CONSELHO DE GOUERNANÇA DO MOUIMENTO TODOS PELA EDUCAÇÃO}

Ball (2014) assevera que as redes políticas constituem uma nova forma de governança, embora não de uma forma única e coerente. Elas colocam em jogo, no processo de produção de políticas, novas fontes de autoridade e, de fato, um "mercado de autoridades". 
Há uma nova mistura dentro da matriz de governança envolvendo relações complexas de interdependência recíproca. Para o autor, a governança em redes tem duas características básicas: desestatização mais ou menos radical, sujeitando organizações públicas à concorrência e ou à entrega da prestação de serviços educacionais às instituições privadas; e reafirma o papel do Estado, mas numa tendência pós-neoliberal, numa nova modalidade que envolve mudanças de governo de burocracia para redes, de prestador de serviços para contratante.

A análise dos processos políticos pela abordagem de redes implica observar os padrões de relação entre os atores, suas interdependências e a forma como esses padrões e interdependências influenciam o processo político (KLIJN, 1998). Para Klijn (1998), as redes de políticas públicas são padrões, mais ou menos estáveis, de relações sociais entre atores interdependentes que tomam forma em torno de problemas e/ou programas políticos.

Assim, ao considerarmos a composição do Conselho de Governança do TPE, composto por até 20 membros, responsável pelo direcionamento político-estratégico do movimento. ${ }^{3}$ Logo, podemos observar, como demonstra o sociograma a seguir os elos que os membros do conselho possuem.

Figura 2 - Vinculos do Conselho de Governança do TPE (2018)

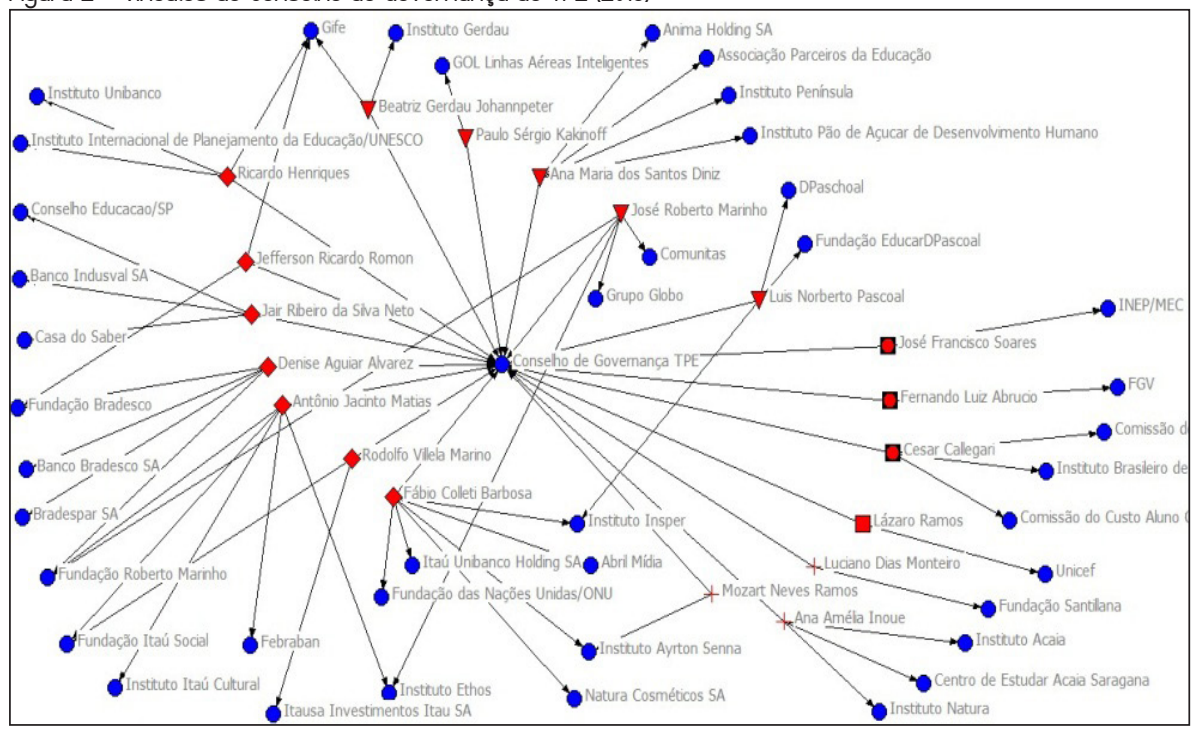

Fonte: o autor. A coleta de dados relacionais foi realizada entre os meses de junho e julho de 2018 e teve como fonte exclusiva de consulta
a Internet. 
A representação da rede acima permite visualizar a presença de diferentes membros da Sociedade Civil que representam diferentes interesses, como grandes empresas, sistema financeiro, organismos multilaterais e governos federal e estaduais. A figura também permite perceber a complexidade das relações entre esses atores. Fazem parte do Conselho 19 membros. $0 \nabla$ (triângulo invertido) representa os setores empresariais. Fazem parte do conselho de governança cinco representantes: Ana Maria Diniz, Beatriz Gerdau, Roberto Marinho, Luiz Roberto Pascoal e Ricardo Kakinoff. $0 \diamond$ (losango) representa os sete (7) membros do sistema financeiro. Fazem parte: Denise Aguiar Alvares (presidente do conselho de governança), Antonio J. Matias, Fabio Barbosa, Jair R. Neto, Jefferson Romon, Ricardo Henriques, Rodolfo Villela Marino. 0 (quadrado redondo) representa os atores que têm vínculo com órgãos do governo federal e fundações privadas. Temos três representantes: Cesar Callegari, José Francisco Soares, Fernando Luis Abrucio. 0 (quadrado) representa uma figura pública do mundo das artes, o ator Lázaro Ramos. 0 sinal + (adição vermelho) representa três atores que têm vínculos com institutos ou fundações: Ana Amélia Inoue, Luciano Monteiro e Mozart Neves. Os - (redondos azuis) são os vínculos que cada um dos atores que compõem o conselho de governança do TPE mantém com os institutos, fundações ou grupos econômicos/financeiros os quais compõem também os conselhos de governança.

Com relação aos grupos da rede ressalta-se que alguns membros apresentam destacada participação em mais de um grupo. É o caso de Fabio Barbosa (presidente da Fundação Itaú Social), membro do Instituto Insper e do Instituto Ayrton Senna; desse faz parte também Mozart Neves Ramos (membro do Conselho Nacional de Educação); no Isnper é membro o empresário Luis Norberto Pascoal. Antônio Jacinto Matias (presidente da Febraban) é membro da Fundação Roberto Marinho e do Instituto Ethos. José Roberto Marinho (presidente do Grupo Globo) é membro da Fundação Roberto Marinho e do Instituto Ethos. Jefferson Ricardo Romon (presidente da Fundação Bradesco) é membro do Grupo de Institutos Fundações e Empresas (GIFE), juntamente com Ricardo Henriques (presidente do Instituto Unibanco) e Beatriz Gerdau (Presidente do Grupo Gerdau).

0 projeto Todos pela Educação para a educação básica brasileira corresponde a uma mudança de perspectiva em relação ao posto que a educação pública ocupa no projeto de desenvolvimento do Brasil. Podemos considerar como início dessa mudança o segundo mandato, em 2007, do governo Luiz Inácio Lula da Silva, com o lançamento do Plano de Desenvolvimento da Educação - PDE, juntamente com o Programa de Aceleração do Crescimento (PAC I e PAC II), a Política de Desenvolvimento Produtivo (PDP) e a expansão dos investimentos da Petrobrás, programas que visavam o desenvolvimento do país para dinamizar os investimentos. Além disso, a interlocução junto aos meios de comunicação viabilizada por uma rede de contatos com empresários e profissionais da mídia demonstra a capacidade que o movimento TPE tem em formar consenso através de estratégias 
midiáticas de presença assídua, seja em jornais impressos de circulação nacional, revistas especializadas em educação e em telejornais sobre os temas ligados à educação. ${ }^{4}$

Diante desse contexto, podemos elencar cinco eixos de propostas e de incidências em políticas públicas para educação promovidas pelo TPE:

a) avaliação/metas - referem-se aos resultados dos instrumentos que medem o desempenho escolar, tais como a Prova Brasil cuja qualidade da educação está pautada por uma cultura de metas reforçada pelo governo com a criação do ldeb;

b) financiamento/gestão - em 2010, após análise do documento do PNE 20112020, o TPE assinalou que o financiamento gradual da educação deveria alcançar a meta de $10 \%$ do Produto Interno Bruto (PIB), no entanto TPE faz uma ressalva ao considerar que o aumento dos recursos é necessário apenas se acompanhado de profissionalização da gestão;

c) formação de docentes - a valorização dos professores é pautada por quatro eixos: salário inicial atraente, plano de carreira, formação inicial e continuada e boas condições de trabalho;

d) arranjos de desenvolvimento da educação - o TPE propõe um regime de colaboração entre os Planos Articulados de Educação e a Lei de Responsabilidade Educacional que devem conformar um Sistema Nacional de Educação em parceria com governo, fundações e institutos de empresas com o objetivo de promover um trabalho em rede para atuar em municípios, com proximidade geográfica e características sociais e econômicas semelhantes afim de solucionar dificuldades na área de educação;

e) lei de responsabilidade educacional - seria um marco regulatório da educação para definir a responsabilidade de cada ente federado na educação, o objetivo visa melhorar o regime de colaboração entre as esferas de governo afim de estabelecer uma distribuição de responsabilidades e responsabilização pelos resultados de aprendizagem (MARTINS, 2013). 


\section{A REDE LATINO-AMERICANA DE ORGANIZAÇÃO DA SOCIEDADE CIUIL PELA EDUCAÇÃO (REDUCA)}

Em 2011, em congresso organizado em Brasília, com o apoio financeiro do Banco Interamericano de Desenvolvimento (BID) e pelo movimento empresarial latino-americano, foi fundada a Rede Latino-americana de Organização da Sociedade Civil pela Educação (Reduca). A Declaração de Brasília (REDE LATINO-AMERICANA DE ORGANIZAÇÃO DA SOCIEDADE CIVIL PELA EDUCAÇÃO, 2011), nome dado ao documento de origem, traça os seguintes objetivos para a organização: trabalhar em conjunto para a garantia do direito à educação de qualidade para toda a criança e jovem; trocar conhecimentos e aprender coletivamente; ter uma voz coletiva no nível regional. A meta definida para a educação na América Latina e Caribe considera que, até o ano de 2024, os estudantes obtenham trajetórias completas de 12 anos de escolaridade e que os países atinjam a média da Organização para a Cooperação e Desenvolvimento Econômico (OCDE) no Programa Internacional de Avaliação de Estudantes (Pisa). As propostas incluem avaliação docente e estudantil, conteúdos educativos, gestão institucional, pesquisas estatísticas etc. De acordo com Lamosa (2017), a reforma educacional que ocorreu nos países membros da Reduca, depois das últimas três décadas, foi realizada após intensa mobilização e articulação de movimentos empresariais.

A Reduca tem como objetivo oferecer espaços de encontros estruturados nos quais estabelecem propostas de políticas educativas com o intuito de colaborar com os Ministérios de Educação. Ela está articulada com o setor empresarial privado de quinze países. São membros fundadores os movimentos: Proyecto Educar 2050 (Argentina); Movimento Todos Pela Educação (Brasil); Educación 2020 (Chile); Empresarios por la Educación (Colômbia); Grupo Faro (Equador); Fundación Empresarial para el Desarrollo Educativo (Fepade/El Salvador); Empresarios por la Educación (Guatemala); Fundación para la Educación Ernesto Maduro Andreu (Ferema/Honduras); Mexicanos Primero (México); Foro Educativo Nicaraguense "Eduquemos"(Nicarágua); Unidos por la Educación (Panamá); Juntos por la Educación (Paraguai); Empresarios por la Educación (Peru); Acción por la Educación (Educa/República Dominicana). No ano de 2018, foi incluído um novo parceiro o ReachingU (Uruguai). Cabe ressaltar que a responsabilidade por coordenar a Reduca é dividida por três organizações fundadoras: Todos Pela Educação (Brasil), Educación 2020 (Chile) e Mexicanos Primero (México).

Uma das questões fundamentais da pesquisa emerge da reflexão sobre as bases de financiamento da Reduca, pois tem duas fontes de financiamento importantes, o Banco Interamericano de Desenvolvimento (BID) e a Comissão Europeia (CE) $)^{5}$.

\footnotetext{
Toda a coleta de dados relacionais foi realizada entre os meses de junho e julho de 2018 e teve como fonte exclusiva de
} consulta a Internet. 
Figura 3 - A Reduca (2019)

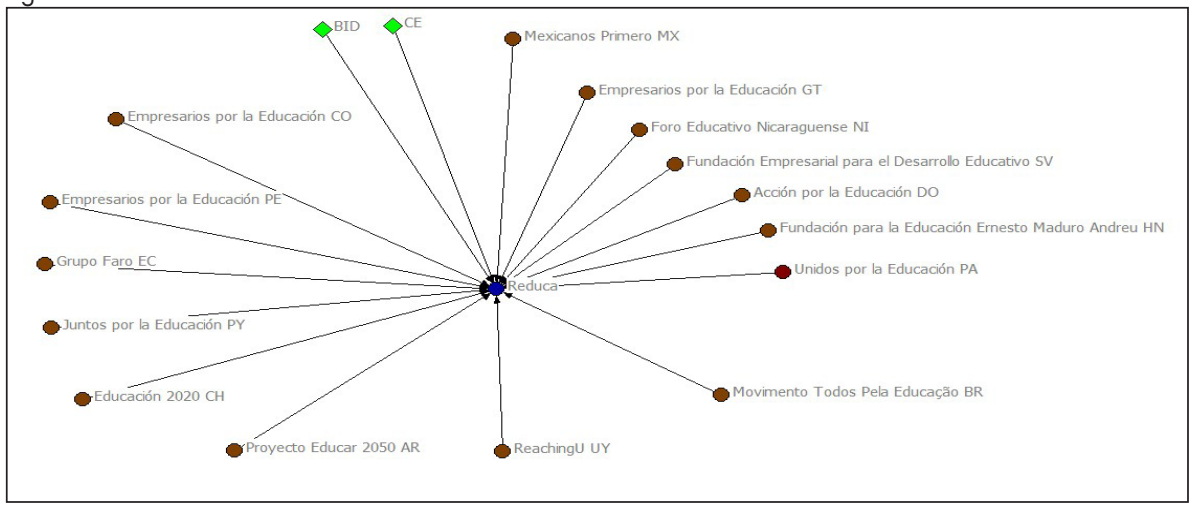

Fonte: o autor.

Segundo Lamosa (2017), os membros da Reduca possuem características similares em vários aspectos, pois apresentam um conselho de governança, produção de agendas de longo prazo, apoio às Parcerias Público Privada (PPP), valorização de programas de inserção do trabalho voluntário em políticas de garantia do direito à educação, demarcação da separação com o governo e com o mercado, definindo-se como parte do "Terceiro Setor" ou da "Sociedade Civil" (que significa a expressão do exercício da cidadania e de origem "apartidária"), além do trabalho estreito com as grandes empresas de comunicação (cabe ressaltar dois exemplos: no Brasil a relação com as empresas do grupo Roberto Marinho; no México, onde a Televisa é uma das associadas do movimento Mexicanos Primeiro).

Tal caminho - do uso da perspectiva de rede para o estudo das organizações como redes sociais, ou seja, ligadas por um tipo específico de relação social - tem se revelado fecundo. As organizações envolvidas na Reduca proporcionam uma infraestrutura vital e um reservatório de competências profissionais que podem ser estudados como "nós", levando à percepção dos imbricamentos ${ }^{6}$ entre elas e os interesses político-econômicos presentes nos processos de formação desta rede transassociativa de interesse de classe.

A formação de uma classe capitalista transnacional, em tempos de globalização financeira, demonstra que as elites do mundo mantêm relacionamentos cada vez mais interconectados. Esses grupos (oligopólios) formam alianças transnacionais estratégicas nas políticas educativas dos Estados nações, cujo processo de concentração de riqueza e poder caracterizam as elites hegemônicas de decisão. 


\section{CONSIDERAÇÕES FINAIS}

As recentes transformações nas políticas educacionais são o sinal de que o capital precisa expandir seus domínios de acumulação por meio de novos setores, no caso, a educação pública. Os grupos institucionais que fazem parte do movimento Todos Pela Educação são, na grande maioria, provenientes do sistema financeiro, centralizam e movimentam grandes volumes de capital para dar sustentação ao projeto de expansão em suas novas áreas de interesse.

A privatização da educação pública é abertamente sustentada pelos responsáveis políticos e muitas vezes recebem apoio generalizado, assim as organizações de interesse do capital têm sob sua gerência três formas diferentes de ação: o uso de própria empresa ou banco, a cooperação financeira e técnica e a forma de associação dos interesses. Isto se evidencia na trajetória da constituição do Movimento Todos pela Educação.

Além disso, a privatização da educação foi, em menor ou maior escala, aceita e implementada pelos últimos governos brasileiros via participação efetiva de membros do Ministério da Educação na composição dos parceiros do TPE. Como atestam Evangelista e Leher (2012, p. 5-6),

[...] ○ ex-ministro da Educação, Fernando Haddad, ○ ex-presidente do Instituto Nacional de Estudos e Pesquisas Educacionais Anísio Teixeira (INEP), Reynaldo Fernandes, os dois últimos ex-Secretários de Educação Básica do MEC, Maria do Pilar Lacerda e Cesar Callegari, este último o Secretário que Costin sucederia, todos são organizadores do TPE.

Assim, retomar essa passagem da história recente nos permite orientar e identificar de que forma a hegemonia financeira pode ser entendida, em sua época e contexto, e qual a contribuição para a compreensão da sociedade contemporânea e de suas relações econômicas e sociais. Não é demais observar que aquilo que aparece como debate sobre a qualidade de ensino público restringe-se ao movimento de organização da burguesia tanto nacional como internacional.

Ademais, a utilização de análise de redes, mesmo que preliminar, possibilitou a visualização da composição das redes de políticas públicas e governança para a interpretação dos dados. Com esse propósito, procuramos apresentar uma análise parcial dos membros que compõem o conselho de governança e dos mantenedores financeiros do movimento TPE. Verificamos que existe uma hegemonia do sistema financeiro com participação de sete membros; ademais existe uma gama diversificada de empresários e quadros políticos e da sociedade civil que atuam em fundações e institutos que também ocupam os conselhos de governança. 
Por fim, verificamos o processo de internacionalização e formação de uma classe capitalista transnacional, formada pela composição da Reduca, de atuação na América Latina e Caribe. Assim como o protagonismo do TPE nas elaborações de políticas públicas para a educação tanto no nível nacional, como um dos responsáveis pela manutenção da rede Reduca.

\section{REFERÊNCIAS}

BALL, S. Educação global S. A.: novas redes políticas e o imaginário neoliberal. Tradução: Janete Bridon. Ponta Grossa: UEPG, 2014.

BALL, S.; YOUNDELL, D. Privatización encubierta en la educación pública, Internacional de la Educación. Bruselas, 2007. Disponivel em: http://www.joanmayans.com/privatizacion_encubierta_de_la_educacion_publica.pdf. Acesso em: 9 nov. 2017.

CAMPANHA LATINO-AMERICANA PELO DIREITO À EDUCAÇÃO. Mapeo sobre Tendencias de la Privatización de la Educación en América Latina y el Caribe. São Paulo: CLADE, 2014.

CHESNAIS, F. 0 capital portador de juros: acumulação, internacionalização, efeitos econômicos e políticos. In: Finança mundializada. São Paulo: Boitempo, 2005.

CHESNAIS, F. A finança mundializada. São Paulo: Boitempo, 2004.

DALE, R. Globalização e educação: demonstrando a existência de uma "Cultura Educacional Mundial Comum" ou localizando uma "Agenda Globalmente Estruturada para a Educação"? Educação e Sociedade, Campinas, v. 25, n. 87, p. 423-460, maio/ago, 2004.

EVANGELISTA, 0; LEHER, R. Todos pela Educação e o episódio Costin no MEC: a pedagogia do capital em ação na política educacional brasileira. In: Trabalho Necessário, ano 10, n. 15, 2012 . Disponível em: http://periodicos.uff.br/trabalhonecessario/article/view/6865/5148 Acesso em: 30 abr. 2019.

GONÇALVES, R. Grupos econômicos: uma análise conceitual e teórica. Revista Brasileira de Economia, Rio de Janeiro: FGV, v. 45, n.4, p.491-518, 1991.

HARVEY, D. Condição pós-moderna. São Paulo: Loyola, 1993.

HARVEY, D. 0 Novo Imperialismo. São Paulo: Loyola, 2003.

KLJIN, E. Redes de políticas públicas: una visión general, 1998. Disponível em: http://revista-redes. rediris.es/webredes/textos/Complex.pdf. Acesso em 15 jul. 2019.

LAMOSA, R. A nova ofensiva do capital na América Latina: Todos pela Educação? Anpuh 2017. Disponivel em: https://www.snh2017.anpuh.org/resources/anais/54/1489967747_ARQUIV0_TextocompletoANPUH2017.pdf. Acesso em: 26 fev. 2019. 
LAVAL, C. A escola não é uma empresa: o neo-liberalismo em ataque ao ensino público. Londrina: Planta, 2004

LEHER, R. Grandes grupos econômicos estão ditando a formação de crianças e jovens brasileiros. Entrevista ao Jornal Brasil de Fato, 2015. Disponivel em: http://antigo.brasildefato.com.br/node/32359. Acesso em: 21 fev. 2019.

MARX, K; ENGELS, F. Manifesto Comunista. São Paulo: Boitempo, 2010, p. 271.

MARX, K. 0 Capital: 0 processo global da produção capitalista Livro III. Tradução: Rubens Enderle. São Paulo: Boitempo, 2017, v. 3.

MARTINS, A. Educação Básica no século XXl: o projeto do organismo "Todos pela Educação". Práxis Educativa, Ponta Grossa, v. 4, n. 1, p. 21-28, jan--jun., 2009.

MARTINS, E. M. Movimento “Todos pela Educação": um projeto de nação para a educação brasileira. 2013. Dissertação. (Mestrado em Educação)-Universidade Estadual de Campinas. Faculdade de Educação, Campinas, SP, 2013.

MÉSZÁROS, I. A educação para além do capital. São Paulo: Boitempo, 2005.

MÉSZÁROS, I. A Crise Estrutural do Capital. São Paulo: Boitempo, 2009.

MINELLA, A. C. Grupos financeiros no Brasil: um perfil econômico e sociopolítico dos maiores credores privados. In: V Workshop Empresa, Empresários e Sociedade. 0 mundo empresarial e a questão social. Porto Alegre, 2-5 maio 2006.

MINTZ, B., \& SCHWARTZ, M.. The power structure of americam business. Chicago: Uinversity of Chicago, 1985.

PEREIRA, J. NOVA ESCOLA E PADRÃO BNCC DE DOCÊNCIA: a formação do professor gerenciado. 2019. Tese (Mestrado no Programa de Pós- graduação em Educação) - Universidade Federal de Santa Catarina, 2019.

PORTUGAL JÚNIOR, J. G. Grupos econômicos: expressão Institucional da unidade empresarial contemporânea. São Paulo, FUNDAP/IESP, 1994.

ROBERTSON, S.; VERGER, A. A origem das parcerias público-privada na governança global da educação. Educação \& Sociedade, v. 33, n. 121, p. 1133-1156, 2012.

SHIROMA, E. 0.; GARCIA, R. M. C.; CAMPOS, R. F. Conversão das "almas" pela liturgia da palavra: uma análise do movimento Todos pela Educação. In: BALL, S.; MAINARDES, J. Políticas educacionais: questões e dilemas. São Paulo: Cortez, 2011. 
URBINI, L. F. Educação integral e capital financeiro: a participação do Itaú Unibanco nas políticas públicas de educação entre 2002 e 2014. 2015. (Mestrado no Programa de Pós-Graduação em Sociologia Política)-Universidade Federal de Santa Catarina, 2015.

UNESCO. Relatório Repensar a educação. 2016. Disponivel em: https://unesdoc.unesco.org/ ark:/48223/pf0000244670. Acesso em: 15 jan. 2019.

Endereço para correspondência: Servidão Cristovão Luis Martins, n. 114, 88063-558, Campeche, Florianópolis; leticia.fiera@gmail.com

Roteiro, Joaçaba, u. 44, n. 3, p. 1-20, set./dez. 2019 | e20932 |E-ISSN 2177-6059 